\title{
Medical emergency teams at The Ottawa Hospital: the first two years
}

\section{[Équipes médicales d'urgence à l'Hôpital d'Ottawa: les deux premières années]}

\author{
Alan D. Baxter MB FRCPC, ${ }^{\star} \dagger$ Pierre Cardinal MD FRCPC, ${ }^{*} \ddagger$ Jonathan Hooper MD FRCPC, ${ }^{*} \dagger$ Rakesh Patel MD ${ }^{*} \ddagger$
}

Purpose: Medical emergency teams (MET) merge earlier-thanconventional treatment of worrisome vital signs with a skilled resuscitation response team, and may possibly reduce cardiac arrests, postoperative complications, and hospital mortality.

Methods: At the two sites of The Ottawa Hospital, MET was introduced in January 2005. We reviewed call diagnoses, interventions, and outcomes from MET activity, and examined outcomes [cardiac arrests, intensive care unit (ICU) admissions, and readmissions] from Health Records and the ICU database. We compared the first fully operational year, 2006, with preMET years, 2003-4.

Results: In 5,74I patient encounters, the teams (nurse, respiratory therapist, and intensivist) responded to I,93I calls over two years, predominantly for high-risk in-patients. As well, there were 3,810 follow-up visits to these patients and to recently discharged ICU patients. In 2006, there were 40.3 calls/team/I,000 hospital admissions, with $71.2 \%$ of in-patient ICU admissions preceded by MET calls. Patient illness severity scores decreased from $4.9 \pm 2.6$ (mean \pm SD) before implementing MET to $2.9 \pm 2.3(P<0.000 \mathrm{I})$ after MET interventions. Intervention on the respiratory system was performed on $72 \%$ of patients. Admission to the ICU occurred in $27 \%$ of MET patients. Compared with the pre-MET period, we observed decreases in: cardiac arrests (from $2.53 \pm 0.8$ to $\mathrm{I} .3 \pm 0.4 / \mathrm{I}, 000$ admissions, $P<0.00 \mathrm{I})$; ICU admissions from in-patient nursing units/month $(42.3 \pm 7.3$ to $37.6 \pm 5.1, P=$ $0.05)$; readmissions after ICU discharge/month (I3.5 \pm 5.1 to $8.8 \pm 4.5, P=0.0 \mathrm{I})$; and readmissions within $48 \mathrm{hr}$ of ICU discharge/month $(4.4 \pm 2.4$ to $2.8 \pm 1.0 \mathrm{ICU}$ readmissions/month, $P=0.01$ ).

Conclusions: Successful implementation of MET reduces patient morbidity and ICU resource utilization.

CAN J ANESTH $2008 / 55: 4 /$ pp 223-231
Objectif : Les équipes médicales d'urgence (EMU) combinent un traitement plus précoce que la pratique traditionnelle des signes vitaux inquiétants à une équipe d'intervention de réanimation expérimentée, ce qui pourrait possiblement réduire les arrêts cardiaques, les complications postopératoires et la mortalité hospitalière.

Méthode : Les EMU ont été introduites dans les deux sites de l'Hôpital d'Ottawa en janvier 2005. Nous avons passé en revue les diagnostics d'appel, les interventions et les pronostics associés à l'activité des EMU, et examiné les devenirs (arrêts cardiaques, admission à l'unité des soins intensifs [USI] et réadmissions) à partir des dossiers médicaux et de la base de données de l'unité des USI. Nous avons comparé la première année complètement opérationnelle, 2006, aux années pré-EMU, 2003-2004.

Résultats : Sur 574 I visites, les équipes (infirmière, inhalothérapeute et intensiviste) ont répondu à 1931 appels en 2 ans, principalement pour des patients hospitalisés à haut risque. De même, il y a eu 3810 visites de suivi pour ces patients et d'autres patients ayant récemment reçu leur congé de I'USI. En 2006, il y a eu 40,3 appels/équipe/l 000 admissions à l'hôpital, et 7I,2 \% des admissions aux USI de patients hospitalisés précédées d'appels EMU. Les scores de sévérité de la maladie des patients ont diminué de 4,9 \pm 2,6 (moyenne $\pm E T$ ) avant la mise en place des EMU à 2,9 $\pm 2,3$ $(P<0,000 I)$ après les interventions des EMU. Des interventions au niveau du système respiratoire ont été effectuées chez $72 \%$ des patients. L'admission à l'USI a eu lieu pour $27 \%$ des patients des EMU. Par rapport à la période pré-EMU, nous avons observé les diminutions suivantes : arrêts cardiaques (de 2,53 $\pm 0,8$ à $I, 3$ $\pm 0,4 / 1000$ admissions, $P<0,0001)$; admissions aux USI de soins hospitaliers/mois $(42,3 \pm 7,3$ à 37,6 $\pm 5, I, P=0,05)$; réadmissions après congé des USI/mois $(I 3,5 \pm 5, I$ à $8,8 \pm 4,5, P=0,0 I)$; et réadmissions dans les 48 heures suivant le congé des USI/mois $(4,4 \pm 2,4$ à 2,8 $\pm 1,0$ réadmissions aux USI/mois, $P=0,01)$.

Conclusion : La mise en place réussie d'EMU réduit la morbidité des patients et l'utilisation des ressources des USI.

From the Departments of Critical Care, ${ }^{*}$ Anesthesia, $\dagger$ and Medicine, $\ddagger$ The Ottawa Hospital, Ottawa, Ontario, Canada. Address correspondence to: Dr. Alan D. Baxter, Department of Anesthesia, The Ottawa Hospital, General Campus, 501 Smyth Road, Ottawa, Ontario K1H 8L6, Canada. Phone 613-737-8187; Fax: 613-737-8189; E-mail: abaxter@ottawahospital.on.ca

Funding: The Ottawa Hospital and the Ministry of Health and Long Term Care, Ontario.

Accepted for publication September 24, 2007.

Revision accepted October 22, 2007.

Final revision accepted January 18, 2008. 
I

$\mathrm{N}$ recent years, The Ottawa Hospital ( $\mathrm{TOH})$, like many Canadian hospitals, has struggled to match available critical care resources with increasing patient load. Factors increasing the demand for intensive care unit (ICU) beds include an expanding and aging population, with increasing, and sometimes unrealistic, patient care expectations and the introduction of more sophisticated, lifeprolonging therapies. Simultaneously, fiscal pressure from governments has resulted in reduced nursing and physician staffing, both in ICUs and on hospital wards. Patients who may benefit from ICU care may remain on wards managed by physicians and nurses who are less familiar with critical illness, when ICU admission may be more appropriate. Many patients who are acutely ill, or who are recovering from surgery, may receive sub-optimal care when changes in their status remain unrecognized or are inadequately treated. $^{1,2}$ Delays in ICU admission may result in further physiological deterioration, leading to prolongation of stay, increased resource utilization, and less favourable outcomes. ${ }^{3}$ Some studies report a higher mortality and a longer ICU stay for patients admitted from hospital wards, compared with those admitted directly from the emergency department, in spite of the expected greater medical and nursing supervision offered within a hospital. ${ }^{4}$

These observations have challenged the current model of provision of intensive care only within the confines of a specialized unit. One innovation involves the creation of medical emergency (MET)/response/ critical care outreach (CCO) teams. These teams have become popular over recent years, following publication of British and Australian studies. ${ }^{5-17}$ The intent of CCO (nurse led) or MET (physician led) units is to identify patients at risk before deterioration to respiratory, circulatory, or multi-system organ dysfunction, thus avoiding ICU admission, or even preventing cardiac arrest.

Interventions rely on two key components - a system utilizing vital signs abnormalities and/or the health care professional's judgment of the risk of deterioration of the patient and a team skilled in resuscitation of critically ill patients. The latter is analogous to the cardiac arrest, trauma, stroke, and myocardial infarction teams already present in many hospitals. After a small pilot project in 2003, we launched METs (named Rapid Assessment of Critical Events, RACE in Ottawa) at both sites of this large tertiary care hospital. Planned hospital-wide rollout in 2004 was delayed until January 2005, to allow our participation in a joint project ${ }^{\mathrm{A}}$ with The University Health Network, Queensway Carleton Hospital, and
Trafalgar Memorial Hospital, and also with associated, partial funding for our team activities from the Ontario Ministry of Health and Long Term Care (MOHLTC). Subsequently, several Canadian centres have also introduced teams, and the MOHLTC is now supporting implementation in about 30 hospitals in Ontario.

Published North American experience ${ }^{15,16,18}$ is limited, and the quality of evidence supporting the introduction of $\mathrm{CCO} / \mathrm{MET}$ has recently been criticized, ${ }^{19-21}$ as most studies used historical controls. Studies with a more robust design include a small British ward-randomized trial ${ }^{22}$ (favourable) and a subsequent, large, randomized controlled trial, MERIT ${ }^{23}$ (equivocal). We considered the outreach concept intuitively appealing and sufficiently evidence-based to introduce locally. We report, herein, two years' experience of program implementation involving 5,741 patient encounters in Ottawa.

\section{Methods}

This is an audit of MET program implementation and outcomes using prospectively collected data with historical comparators. Where necessary, Research Ethics Board approval was obtained for chart review for data extraction.

\section{Setting}

The Ottawa Hospital, General and Civic tertiary care, in-patient sites admit a wide range of adult medical and surgical patients, with some specialties being segregated at one site. Approximately 900 beds are available for approximately 47,000 admissions and 25,000 surgical procedures per year. There are two closed ICUs with approximately 24 beds each. The Civic has general medical and neurosurgical intermediary care units, with thoracic, surgical/neurological, and cardiology intermediary care units at the General. Cardiac surgery and cardiology is at a separate site not covered by MET. There is an acute pain service at both sites, but no hospitalists. The nursing density and medical staffing did not change during the time of program review.

\section{Objectives and rationale of MET teams}

1) To empower any hospital health care provider to recognize and to respond to physiologic distress by using vital signs and clinical acumen; to initiate early

A "Expanding the walls". A collaborative approach to pilot Critical Care Outreach Teams in Ontario. The Ottawa Hospital \& University Health Network. 
TABLE I The Ottawa Hospital medical emergency team call activation criteria

\begin{tabular}{ll}
\hline Airway & - threatened, stridor, excessive secretions \\
Breathing & - respiratory rate $\leq 8, \geq 30 \cdot \mathrm{min}^{-1}$ \\
Circulation & - systolic blood pressure $\leq 90 \mathrm{mmHg}$, \\
& $\geq 200 \mathrm{mmHg}, \geq 40 \mathrm{mmHg}$ drop \\
& decrease \\
& - heart rate $\leq 40 \cdot \mathrm{min}^{-1}, \geq 130 \cdot \mathrm{min}^{-1}$ \\
& - decreased $>2 \mathrm{Glasgow} \mathrm{coma} \mathrm{scale}$ \\
Level of consciousness & $<90 \%$ on $50 \% \mathrm{O}_{2}$ or $6 \mathrm{~L} \cdot \mathrm{min}^{-1}$ \\
Oxygen saturation & $<100 \mathrm{~mL}$ over four hours \\
Urine output & Health care worker "worried" about the patient, needs medical \\
assistance, failure to respond to treatment
\end{tabular}

Any one of these criteria is reason to activate the medical emergency team.

patient resuscitation, to prevent progressive physiological deterioration, to reduce patient morbidity, and to avoid ICU admission or even death;

2) To avoid inappropriate ICU admissions by discussion of end-of-life care options;

3) To minimize ICU readmissions by $48 \mathrm{hr}$ postdischarge follow-up, to facilitate the transition to ward care.

Some critically ill patients, for whom ICU admission cannot be avoided, might still benefit from the earlier MET resuscitation and expedited admission to ICU, thus preventing progression to irreversible organ failure and death. We aimed to improve patient care and outcomes, and to improve utilization of limited and expensive ICU resources.

\section{Description of teams}

The bedside nurse, or other hospital health care provider, can activate MET $24 \mathrm{hr}$ daily if specific vital sign thresholds (derived from other reports) $)^{5,7,8,13,14,24}$ are reached (Table I). These specific vital sign thresholds provide simple, objective criteria for calling for assistance, plus a non-specific "concern" about patients who appear seriously ill, yet don't cross these thresholds.
Each Ottawa MET consists of a critical care nurse, a respiratory therapist, and an intensivist, all available to help in the ICU when not involved in MET activities. Coverage is described in Table II. Most of these team members have completed the acute critical event simulation (ACES) course. As well, there are planned team activities including: procedure assistance, endof-life counselling, health-care provider education, and $48 \mathrm{hr}$ ward follow-up after initial consultation or ICU discharge. Support from an intensivist, by telephone or call back, is available as needed. The MET resuscitation cart is designed to provide critical care hospital-wide. It is equipped for; monitoring and resuscitation of acute airway, for breathing and circulatory emergencies, and for safe patient transfer to imaging facilities or to high dependency units. The patients admitting service is called simultaneously to provide background information and to assist with assessment, resuscitation, liaison for ongoing care, and teaching. The MET team does not respond to cardiac arrest calls.

\section{Implementation}

We used a multi-disciplinary and team building approach to delegate responsibilities and to determine calling criteria, activation mechanism, equipment needs, educational needs and delivery thereof, job descriptions, marketing strategies for hospital personnel, and budgeting. Various stakeholders consulted before implementation included; senior administrators, ward physicians and nurses, residents, respiratory therapists, and critical care nurses. We remained flexible to the concerns of stakeholders, while maintaining key principles. Marketing strategies included: hospital-wide lectures, assistance of nurse educators, job fair information dissemination, new employee orientation packages, distribution of calling cards, and large colourful posters placed throughout the hospital. During the early weeks after team implementation in January 2005, we conducted repeated in-services with nursing unit personnel about the MET concept and their interaction with the team. These activities

TABLE II Medical emergency team personnel and coverage

\begin{tabular}{|c|c|c|}
\hline Personnel & Monday to Friday coverage & Weekend coverage \\
\hline ICU RN & 24 hr daily & 24 hr daily \\
\hline \multirow[t]{2}{*}{ ICU respiratory therapist } & 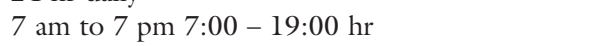 & 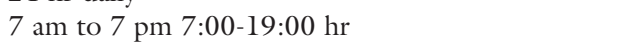 \\
\hline & On-call within hospital 7 pm - 7 am 19:00-7:00 & On-call within hospital $7 \mathrm{pm}-7$ am 19:00-7:00 hr \\
\hline \multirow[t]{2}{*}{ Intensivist } & $7: 30$ am to $5 \mathrm{pm} \mathrm{7:30-17:00}$ & On-call intensivist $24 \mathrm{hr}$ daily $7: 30$ am to $5 \mathrm{pm}$ daily \\
\hline & On-call intensivist $5 \mathrm{pm}$ to $7: 30 \mathrm{am}$ 17:00-7:30 & On-call intensivist $5 \mathrm{pm}$ to $7: 30 \mathrm{am}$ \\
\hline ICU resident(s) & $5 \mathrm{pm}$ to $7: 30$ am 17:00-7:30 & $5 \mathrm{pm}$ to $7: 30$ am 17:00-7:30 \\
\hline
\end{tabular}

$\mathrm{ICU}=$ intensive care unit, $\mathrm{RN}$ = registered nurse. 
were essential to achieve a gradual increase in MET activity to $24 \mathrm{hr}$ /day and seven days/week by March 2005. To follow the effectiveness of implementation, we documented the number of MET calls and the ICU in-patient admissions, with or without prior MET calls.

\section{Training}

Nurse educators, respiratory therapist educators, and physicians modified ACES (which targets physicians providing early resuscitation for critically ill patients) to meet the learning needs of MET personnel in a two-day course. On-going bedside education was provided at each MET call, with patient encounter discussion, diagnosis and treatment review, and feedback about team performance during resuscitation. One important role played by MET was in educating ward personnel (both nurses and junior physicians) in the use of activation criteria, and in the importance of early recognition and treatment of critically ill patients.

\section{Data collection}

We developed a data collection tool and database for MET members to track all calls; to record patient demographics, co-morbidities, and illness severity; and to document MET activities and interventions during each consult and follow-up visit. We prospectively collected outcome data, including changes in patient illness severity, as a result of MET intervention using the multiple organ dysfunction score, ${ }^{25}$ patient disposition, mortality, and ICU length of stay and readmission rates. ${ }^{5-17}$ Initiators of MET calls were given satisfaction questionnaires after each call, in order to obtain feedback regarding various aspects of team interaction and function (familiarity with call criteria, role at the call, quality of educational opportunity, communications with team, etc.) and to identify areas of potential improvement. Health records chart review coding using ICDI 0 provided monthly information about hospital admissions, mortality, postoperative complications (respiratory failure, stroke, severe sepsis, acute renal failure, myocardial infarction, and pulmonary embolism), ${ }^{14}$ and cardiac arrests. Our ICU database personnel recorded ICU patient admission and outcome data daily and provided additional information including; with, or without, a preceding MET call, illness severity, mortality, and length of stay. Calls to MET, and to the cardiac arrest team, were recorded by the hospital communications department and were reported monthly. The hospital standardized mortality ratio ${ }^{26}$ (HSMR, the ratio of actual to expected deaths, is based on diagnostic groups that account for $80 \%$ of deaths, and excludes anticipated deaths in e.g., palliative patients) was obtained from the Canadian Institute for Health Information.

Data for each site were collected separately, but, for clarity and brevity, are detailed collectively in our report for the The Ottawa Hospital. Data were available for two years before (2003-4, retrospective) and for two years after (2005-6, prospective) MET introduction in January 2005, except for postoperative data for the last three months of 2006 (health records coding problems).

\section{Data analysis}

There was a gradual increase in MET activity during 2005 , and here we report outcome data for 2006, the first full calendar year of operation, compared with 2003 and 2004, before MET implementation. Statistical analysis of outcome data was performed with Student's $t$ test and non-parametric Wilcoxon test, as appropriate, using SAS version 9.1 (SAS Institute Inc., Cary, NC, USA). Primary outcomes were the number of; cardiac arrests ("Code Blue" calls and Health Records coding), in-patient ICU admissions and readmissions, and hospital mortality (overall and HSMR).

Secondary outcomes were; major postoperative complications, mortality and unplanned, postoperative ICU admissions, post-cardiac arrest ICU admissions and outcomes, and hospital mortality of ICU survivors.

\section{Results}

Medical emergency team activities (Table III)

Activities of the site-specific MET teams were similar, with many patients receiving multiple interventions. Each team received an average of two calls/day during the first year of activity, increasing through 2005 to 2.5 calls/day in 2006 (Figure), distributed evenly through $24 \mathrm{hr}$. In addition, each team saw a mean of three follow-up patients each day, either after ICU discharge or after a previous MET call. End-of-life care issues were discussed and the appropriate level of care was determined de novo in $8 \%$ of patients, and chart documentation was clarified in $20 \%$ of patients.

\section{Outcomes (Table IV)}

Results are reported for 2006, the first full calendar year of MET operation, compared with the preMET baseline years of 2003 and 2004. There were improvements in most parameters, with significant reductions in unanticipated cardiac arrests, postoperative complications, and in-patient ICU admissions and readmissions. 
TABLE III Medical emergency team activities at The Ottawa Hospital 2005-6, total calls ( $n=1,931$ over two years)

\begin{tabular}{|c|c|c|}
\hline \multirow[t]{4}{*}{ Calls initiated by } & Registered nurse & $67 \%$ \\
\hline & Resident & $15 \%$ \\
\hline & Staff physician & $7 \%$ \\
\hline & Other & $1 \%$ \\
\hline \multirow[t]{10}{*}{ Admitting service } & Medicine & $17 \%$ \\
\hline & General Surgery & $12 \%$ \\
\hline & Neurosurgery / Neurology & $12 \%$ \\
\hline & Medical / Radiation oncology & $9 \%$ \\
\hline & Orthopedics & $8 \%$ \\
\hline & Thoracic surgery / Respirology & $7 \%$ \\
\hline & Vascular surgery & $7 \%$ \\
\hline & Hemoncology & $6 \%$ \\
\hline & Nephrology / Cardiology & $5 \%$ \\
\hline & Miscellaneous & $17 \%$ \\
\hline \multirow[t]{5}{*}{ Most frequent diagnoses } & Cardiac & $26 \%$ \\
\hline & Respiratory & $23 \%$ \\
\hline & Sepsis & $10 \%$ \\
\hline & Over-sedation & $4 \%$ \\
\hline & Miscellaneous & $23 \%$ \\
\hline \multirow[t]{2}{*}{ Duration of calls } & Initial visits $>60 \mathrm{~min}$ & $47 \%$ \\
\hline & Follow-up visits $<30 \mathrm{~min}$ & $81 \%$ \\
\hline \multirow[t]{10}{*}{ Interventions } & Respiratory: $\quad$ total respiratory & $72 \%$ \\
\hline & Oxygen therapy & $39 \%$ \\
\hline & Non-invasive ventilation & $7 \%$ \\
\hline & Intubation & $5 \%$ \\
\hline & Tracheostomy care & $6 \%$ \\
\hline & Bronchodilators & $15 \%$ \\
\hline & Cardiovascular: total cardiovascular & $63 \%$ \\
\hline & Fluids & $32 \%$ \\
\hline & Diuretics & $10 \%$ \\
\hline & Other cardiovascular & $6 \%$ \\
\hline \multirow[t]{2}{*}{ Resuscitation status } & Determined by team & $8 \%$ \\
\hline & Documentation improved & $20 \%$ \\
\hline Multiple organ dysfunction score & Initial visit & $4.9 \pm 2.6$ \\
\hline mean \pm standard deviation & Follow-up visit & $2.9 \pm 2.3$ \\
\hline \multirow[t]{3}{*}{ Disposition } & Patients managed on nursing unit & $67 \%$ \\
\hline & Transfer to intensive care unit & $27 \%$ \\
\hline & Transfer to coronary care unit/step-down unit & $6 \%$ \\
\hline \multirow[t]{3}{*}{ Satisfaction questionnaire responses } & Positive/strongly positive & $97 \%$ \\
\hline & Neutral & $2.3 \%$ \\
\hline & Negative & $0.7 \%$ \\
\hline
\end{tabular}

After two years, $71 \%$ of ICU admissions were preceded by a MET call, rather than a conventional consultation initiated by the attending service, and there were 40.3 calls/team /1,000 hospital admissions, indicating successful implementation.

The MET interventions were associated with significant improvements in organ function, indicated by the multiple organ dysfunction $\operatorname{scores}^{24}$ at the initial encounter and subsequent follow-up. Initial encounter scores averaged $4.9 \pm 2.6$, similar to the median score of ICU patients in the first $24 \mathrm{hr}$ after admission, ${ }^{24}$ but decreased to $2.9 \pm 2.3(P<0.0001)$ at follow-up after team interventions. Compared to baseline years 2003 and 2004, throughout 2006 we observed a 38\% reduction in "Code Blue" calls from 5.5 to 3.4/1,000 admissions $(P<0.001)$, and a $62 \%$ reduction in health records coded unanticipated cardiac arrests (which excludes respiratory arrests and false alarms) from 2.53 to $0.95 / 1,000$ admissions $(P<0.001)$. 


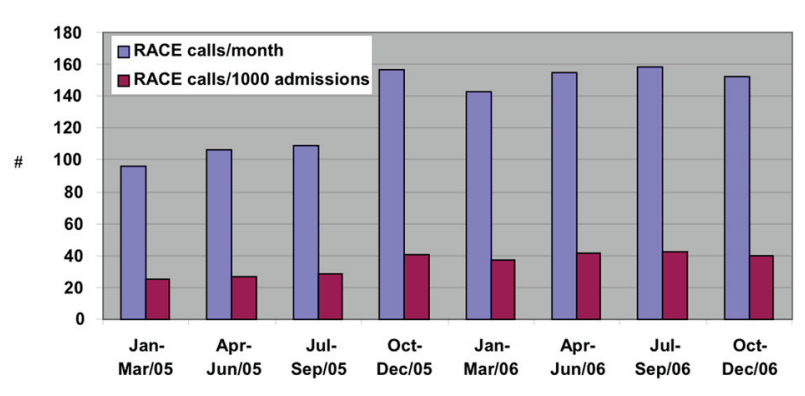

FIGURE The number of calls to the medical emergency teams, called RACE ("Rapid Assessment of Critical Events") in Ottawa, throughout 2005 and 2006.

There were fewer ICU admissions from in-patient wards/month, $42.3 \pm 7.3$, to $37.6 \pm 5.1(P=0.05)$, fewer patient readmissions to ICU, both overall $(P$ $=0.01)$ and within $48 \mathrm{hr}$ of discharge $(P=0.01)$. Major postoperative complications ${ }^{14}$ decreased from $69 \pm 25.3 / 1,000$ surgical procedures pre-MET to 60 $\pm 23.8 / 1,000$ procedures in 2006 (data available for the first nine months $)(P=0.01)$.

Other outcome variables showed trends towards: lower hospital mortality of ICU survivors; shorter ICU length of stay of ICU patients admitted after a MET call; lower postoperative mortality; and fewer unplanned postoperative ICU admissions. While the overall hospital mortality was unchanged, the HSMR decreased below the national average (100) in 2006 (Table IV).

Satisfaction questionnaires, completed by ward personnel after team interventions, revealed a high degree of satisfaction, with $97 \%$ of the responses to the twelve item questionnaire being positive/strongly positive.

\section{Discussion}

We have found that implementation of MET at the $\mathrm{TOH}$ has resulted in a significant reduction in the number of unanticipated cardiac arrests and unplanned in-patient ICU admissions. There was an overall reduction in readmissions and a decline in readmissions within $48 \mathrm{hr}$ of ICU discharge. The number of ICU deaths, after in-hospital cardiac arrest, and the number of postoperative complications has also decreased. In addition, we observed favourable trends regarding; length of ICU stay, ICU mortality of patients admitted after a MET call, and decreased post-ICU, in-hospital mortality.

Several studies ${ }^{5-17}$ have also reported fewer cardiac arrests, postoperative complications and deaths, and reduced hospital mortality achieved from MET/ CCO. Most studies have used historical controls which, because of the difficulties and the expense of prospective randomization, may be confounded by other known or unknown variables that might potentially influence outcomes.

MERIT, ${ }^{23}$ the largest, randomized trial evaluating MET, cluster randomized 23 Australian hospitals to either continue functioning with a cardiac arrest team only $(n=11)$ or to introduce MET. During the six-month study, there was no significant difference between control and MET hospitals in the composite endpoint of cardiac arrest, unplanned ICU admissions, or unexpected deaths. However, MERIT had implementation limitations, largely ignored by many reviewers, ${ }^{19-21}$ which make interpretation difficult. The MET system is complex, difficult to implement, and appears to have been underutilized by the ward health care professionals in the MERIT study experimental arm. There were 3.1 cardiac arrest team calls $/ 1,000$ admissions in the control hospitals compared to 8.7 MET calls/1,000 admissions in the MET hospitals. This small increase suggests that MET was not contacted for all patients meeting call criteria, and, indeed, the frequency of vital sign measurement itself, before events, was relatively low (38\%). In contrast, after six months at the TOH, we received $26 \mathrm{MET}$ calls $/ 1,000$ admissions, increasing to $40 \mathrm{MET}$ calls/1,000 admissions in 2006, suggesting more effective implementation than in the MERIT study (Figure). Better implementation correlated with outcomes; cardiac arrests decreased from 2.5 to $1.6 / 1,000$ admissions after six months, and decreased further to $0.95 / 1,000$ admissions by 2006 .

Also, in MERIT, the MET was called to only 34\% of in-patients requiring ICU admission; yet, all such patients must have met at least one call criterion. After six months of MET, $49 \%$ of in-patient ICU admissions at the TOH were after-MET calls, increasing to $71 \%$ after two years. Again, this suggests a more effective implementation than in the MERIT study, where the implementation period may have been too short for effective introduction of this paradigm-shifting, multi-faceted intervention. While our implementation was clearly superior, $29 \%$ of our patients admitted to the ICU did not trigger a MET call. Some of these patients may not have had premonitory vital sign abnormalities (e.g., pulmonary embolism); nevertheless, there are still instances of sub-optimal use of the call system. Even now the TOH implementation is not perfect.

Cardiac arrests decreased in hospitals in both groups in the MERIT study (controls 2.61 to $1.64 / 1,000$ 
TABLE IV Medical emergency team and outcomes at The Ottawa Hospital

\begin{tabular}{|c|c|c|c|}
\hline Outcome & Pre-MET - 2003-4 & Post-MET - 2006, first full calendar year & P value \\
\hline $\begin{array}{l}\text { ICU admissions from } \\
\text { in-patient nursing units } \\
\text { per month }\end{array}$ & - $42.3 \pm 7.3$ & $\begin{array}{l}\text { - } 37.6 \pm 5.1 \text { in } 2006 \\
\text { - } 71.1 \% \text { preceded by MET call } \\
\text { - } \text { patient mortality } 31.4 \% \text { vs } \\
32.7 \% \text { for non-MET admitted } \\
\text { ICU patients } \\
\text { - } \text { ICU length of stay } 7.65 \text { days for } \\
\text { MET patients, } 8.7 \text { days non-MET patients }\end{array}$ & - $P=0.05$ \\
\hline $\begin{array}{l}\text { Unanticipated cardiac arrests } \\
\text { per 1,000 hospital admissions } \\
\text { - Code Blue calls } \\
\text { - Health records coded } \\
\text { cardiac arrests }\end{array}$ & $\begin{array}{l}-5.5 \pm 1.3 \\
\text { - } 2.5 \pm 0.8\end{array}$ & $\begin{array}{l}\text { - } 3.4 \pm 0.8 \\
\text { - } 1.3 \pm 0.4\end{array}$ & $\begin{array}{l}-P<0.001 \\
\text { - } P<0.001\end{array}$ \\
\hline $\begin{array}{l}\text { ICU admissions post-cardiac } \\
\text { arrest per month }\end{array}$ & $\begin{array}{l}\text { - } 3.4 \pm 2 \\
\text { - } \text { Subsequent deaths } 2.5 \pm 1.3 \\
\text { - } \text { ICU patient days } 14.9 \pm 20.1\end{array}$ & $\begin{array}{l}-2.4 \pm 1.4 \text { in } 2006 \\
\text { - } \text { Subsequent deaths } 1.3 \pm 0.9 \\
\text { - } \text { ICU patient days } 7.4 \pm 11.2\end{array}$ & - $P=0.01$ \\
\hline ICU readmissions per month & $\begin{array}{l}\text { - Total } 13.5 \pm 5.1 \\
\text { - }<48 \text { hr of ICU discharge } 4.4 \pm 2.4\end{array}$ & $\begin{array}{l}\text { - Total } 8.8 \pm 4.5 \\
\text { - }<48 \text { hr of ICU discharge } 2.8 \pm 1\end{array}$ & $\begin{array}{l}\text { - } P=0.01 \\
\text { - } P=0.01\end{array}$ \\
\hline $\begin{array}{l}\text { In-hospital mortality of } \\
\text { ICU survivors }\end{array}$ & - $9 \%$ & - $7.1 \%$ in 2006 & - $P=0.07$ \\
\hline $\begin{array}{l}\text { Postoperative outcomes / } \\
\text { 1,000 in-patient surgeries } \\
\text { - Total complications } \\
\text { - Mortality } \\
\text { - Unplanned ICU admissions }\end{array}$ & $\begin{array}{l}\text { - } 68.8 \pm 25.3 \\
\text { - } 11.4 \pm 10.6 \\
\text { - } 4.5 \pm 6.7\end{array}$ & $\begin{array}{l}\text { - } 60.1 \pm 23.8 \\
\text { - } 9.6 \pm 9.8 \\
\text { - } 3.7 \pm 6.1\end{array}$ & - $P=0.01$ \\
\hline Hospital mortality & - $3.57 \%$ overall & - $3.55 \%$ overall & \\
\hline
\end{tabular}

admissions, MET 1.60 to $1.31 / 1,000$ admissions), suggesting that control teams were referred non-cardiac arrest patients and were functioning as MET (i.e., cross contamination). Furthermore, MET hospitals in the MERIT study had low pre-study event rates, and less room for improvement with the introduction of MET.

The MERIT study illustrates the implementation difficulties of MET, and cannot provide unequivocal evidence that acute resuscitation teams are without benefit. Lack of evidence does not equate with lack of benefit, particularly for interventions with little risk to the patient ${ }^{27}$ such as MET.

We were relatively successful at implementing MET in our hospital. Enthusiastic and committed team members were essential (physicians, nurses, respiratory therapists), along with philosophical support from specialties and subspecialties, and financial assistance from hospital administration and/or provincial health ministries. At $\mathrm{TOH}$, the education of medical students and residents in managing acutely ill patients was a concern. In our belief that each MET call is an ideal situation for teaching and learning acute resuscitation skills under supervision, we introduced MET as an elective resident rotation. The resuscitation teams were enthusiastically received and supported by the vast majority of the ward health care professionals, who gave positive responses to the satisfaction questionnaires. However, we did experience several problems with the implementation of this new service. Inevitably, some of our colleagues initially felt that we were interfering with their patient management, rather than assisting and working with them, and they discouraged nurses from calling MET. Even now, call criteria are not being used optimally, and it is difficult to introduce lasting changes to longstanding 
work practices. We address these issues with ongoing in-service training and education to maintain, and to improve upon, the benefits we have thus far accomplished.

Medical emergency team combines earlier detection of problems with earlier skilled intervention. We did not seek to determine which component is more important or is more responsible for the improvements observed, or, as suggested by others, whether the educational component alone is adequate. ${ }^{20}$ Such suggestions may, or may not be, correct and, in the absence of evidence, are purely speculative. As for $\mathrm{TOH}$, we have observed significant improvements in patient outcomes with the package.

The strengths of our report include; the duration of the audit, the magnitude of patients involved, and the evidence of successful implementation. It is the first such report from the Canadian health care system, and it illustrates the potential benefits achievable with $\mathrm{CCO} / \mathrm{MET}$ in Canada. Like most other reports of $\mathrm{CCO} / \mathrm{MET}$, we used historical controls; however, this would be more problematic if we were performing a study such as MERIT, rather than describing our experience with program implementation, where bias is less relevant. Bias is to be expected with our satisfaction score data; however, the activity data are largely descriptive, and the outcome data are collected and reported at arms length from clinical patient management. Other factors may contribute to the observed outcome improvements, but there were no major, concurrent, structural, or organizational changes at the TOH during the years around MET implementation. Our perioperative improvements coincided with the implementation of MET; nevertheless, possible contributory factors could include changes in surgical technique (e.g., increasing use of laparoscopy for more major surgery) and increased use of epidural analgesia and beta blockers. ${ }^{28}$

\section{Conclusions}

We report two years' experience with CCO/MET at the TOH, and our data support successful implementation. While we used historical controls in our audit, there were no other major changes in patient care affecting observed outcome improvements. Many of the parameters we continue to follow are progressively improving with time, and ongoing education of ward personnel is essential to maintain the gains.

That earlier intervention improves outcome is intuitively reasonable, and the MERIT study illustrates the difficulty of implementing a large, prospective, randomized trial in this area. Our results suggest that MET offers benefits to the Canadian health care system, as in other countries. The MET approach has been effective in this large, tertiary teaching hospital, and the reduction of ICU admissions and readmissions has allowed redistribution of resources to other patients. Other institutions in Canada are introducing $\mathrm{CCO} / \mathrm{MET}$ with various team structures, and, hopefully, they will find this description of our experience helpful and encouraging.

\section{Acknowledgements}

We thank Mohammed Kabir for data management, Marlene Beehler for intensive care unit outcome data, Steve Doucette for statistical assistance, Ron Greene and Carol Beaudoin for health records assistance, RACE team members for their enthusiastic clinical efforts, and the MOHTLC and the TOH for funding the project.

\section{References}

1 McQuillan P, Pilkington S, Allan A, et al. Confidential inquiry into quality of care before admission to intensive care. BMJ 1998; 316: 1853-8.

2 McGloin H, Adam S, Singer M. The quality of pre-ICU care influences outcome of patients admitted from the ward. Clin Intensive Care 1997; 8: 104.

3 McGloin H, Adam SK, Singer M. Unexpected deaths and referrals to intensive care of patients on general wards. Are some cases potentially avoidable? J Roy Coll Phys Lond 1999; 33: 255-9.

4 Goldhill DR, Sumner A. Outcome of intensive care patients in a group of British intensive care units. Crit Care Med 1998; 26: 1337-45.

5 Lee A, Bishop G, Hillman KM, Daffurn K. The medical emergency team. Anaesth Intensive Care 1995; 23: 183-6.

6 Goldhill DR, Worthington L, Mulcaby A, Tarling M, Sumner A. The patient-at-risk team: identifying and managing seriously ill ward patients. Anaesthesia 1999; 54: 853-60.

7 Bristow PJ, Hillman KM, Chey T, et al. Rates of in-hospital arrests, deaths, and intensive care admissions: the effect of a medical emergency team. Med J Aust 2000; 173: 236-40.

8 Hillman K, Parr M, Flabouris A, Bishop G, Stewart $A$. Redefining in-hospital resuscitation: the concept of the medical emergency team. Resuscitation 2001; 48: 105-110.

9 Salamonson $\Upsilon$, Kariyawasam A, van Heere B, O'Connor $C$. The evolutionary process of medical emergency team (MET) implementation: reduction in unanticipated ICU transfers. Resuscitation 2001; 49: 135-41.

10 Riley B, Faleiro $R$. Critical care outreach: rationale and development. BJA CEPD Reviews 2001; 5: 146-9. 
11 Buist MD, Moore GF, Bernard SA, Waxman BP, Anderson JN, Nguyen TV. Effects of a medical emergency team on reduction of incidence of and mortality from unexpected cardiac arrests in hospital: preliminary study. BMJ 2002; 324: 387-90.

12 Ball C, Kirkby M, Williams S. Effect of the critical care outreach team on patient survival to discharge from hospital and readmission to critical care: nonrandomised population based study. BMJ 2003; 327: 1014.

13 Bellomo R, Goldsmith D, Uchino S, et al. A prospective before-and-after trial of a medical emergency team. Med J Aust 2003; 179: 283-7.

14 Bellomo R, Goldsmith D, Uchino S, et al. Prospective controlled trial of effect of medical emergency team on postoperative morbidity and mortality rates. Crit Care Med 2004; 32: 916-21.

15 DeVita MA, Braithwaite RS, Mahidhara R, et al. Use of medical emergency team responses to reduce hospital cardiac arrests. Qual Saf Health Care 2004; 13: 251-4.

16 Braithwaite RS, De Vita MA, Mahidhara R, et al. Use of medical emergency team (MET) responses to detect medical errors. Qual Saf Health Care 2004; 13: 255-9.

17 Kenward G, Castle N, Hodgetts T, Shaikh L. Evaluation of a medical emergency team one year after implementation. Resuscitation 2004; 61: 257-63.

18 Galhotra S, DeVita MA, Simmons RL, Schmid A; Members of the Medical Emergency Response Improvement Team (MERIT) Committee. Impact of patient monitoring on the diurnal pattern of medical emergency team activation. Crit Care Med 2006; 34 : 1700-6.

19 Forster AJ, Shojania KG, van Walraven C. Improving patient safety: moving beyond the "hype" of medical errors. CMAJ 2005; 173: 893-4.

20 Winters BD, Pham J, Pronovost PJ. Rapid response teams - walk don't run. JAMA 2006; 296: 1645-7.

21 Winters BD, Pham JC, Hunt EA, Guallar E, Berenholtz $S$, Pronovost PJ. Rapid response systems: a systematic review. Crit Care Med 2007; 35: 1238-43.

22 Priestley $G$, Watson W, Rashidian A, et al. Introducing critical care outreach: a ward-randomised trial of phased introduction in a general hospital. Intensive Care Med 2004; 30: 1398-404.

23 Hillman K, Chen J, Cretikos M, et al. Introduction of the medical emergency team (MET) system: a clusterrandomised controlled trial. Lancet 2005; 365: 2091-7.

24 Hodgetts TJ, Kenward G, Vlachonikolis IG, Payne S, Castle N. The identification of risk factors for cardiac arrest and formulation of activation criteria to alert a medical emergency team. Resuscitation 2002; 54 : 125-31.
25 Marshall JC, Cook DJ, Christon NV, Bernard GR, Sprung CL, Sibbald WJ. Multiple organ dysfunction score: a reliable descriptor of a complex clinical outcome. Crit Care Med 1995; 23: 1638-52.

26 Jarman B, Bottle A, Aylin P, Browne M. Monitoring changes in hospital standardized mortality ratios. BMJ 2005; 330: 329.

27 Kerridge RK, Saul WP. The medical emergency team, evidence-based medicine and ethics. Med J Aust 2003; 179: 313-5.

28 Baxter AD, Kanji S. Protocol implementation in anesthesia: beta-blockade in non-cardiac surgery patients. Can J Anesth 2007; 54: 114-23. 